\title{
A Sudden Beevor's Sign
}

Fidias E. Leon-Sarmiento, MD, PhD; Edgardo A. Bayona, MD; and Jaime Bayona-Prieto, PhT, NRh

A 14-year-old Colombian girl developed sudden spastic paraparesis 2 days before going to a rural hospital in northeast Colombia where a diagnosis of multiple sclerosis was made. A battery of neurological tests was suggested to confirm the multiple sclerosis diagnosis, which could not be afforded by the patient's family. Due to the lack of facilities in her hometown, she was sent to the closest university hospital. Upon arrival at the emergency unit, she was found with spastic paraparesis, absent cutaneous reflex below the thoracic vertebra T10, loss of proprioception in her lower limbs, exaggerated knee and Achilles tendon reflexes, bilateral feet extensor responses, and urinary continence. Familial and personal past medical history was unremarkable. She emphasized that the medical problem came on suddenly 3 days before visiting the university hospital after feeling a knife-like pain at the mid-thoracic level. Beevor's sign ${ }^{1}$ was present (Figure 1). A myelovascular disease was considered and magnetic resonance imaging (MRI) performed to the spinal cord. MRI showed a medullary infarction from T10 to T12, and anterior spinal artery syndrome was considered. Medical and neurorehabilitation measures were started immediately. The patient was lost in follow-up.

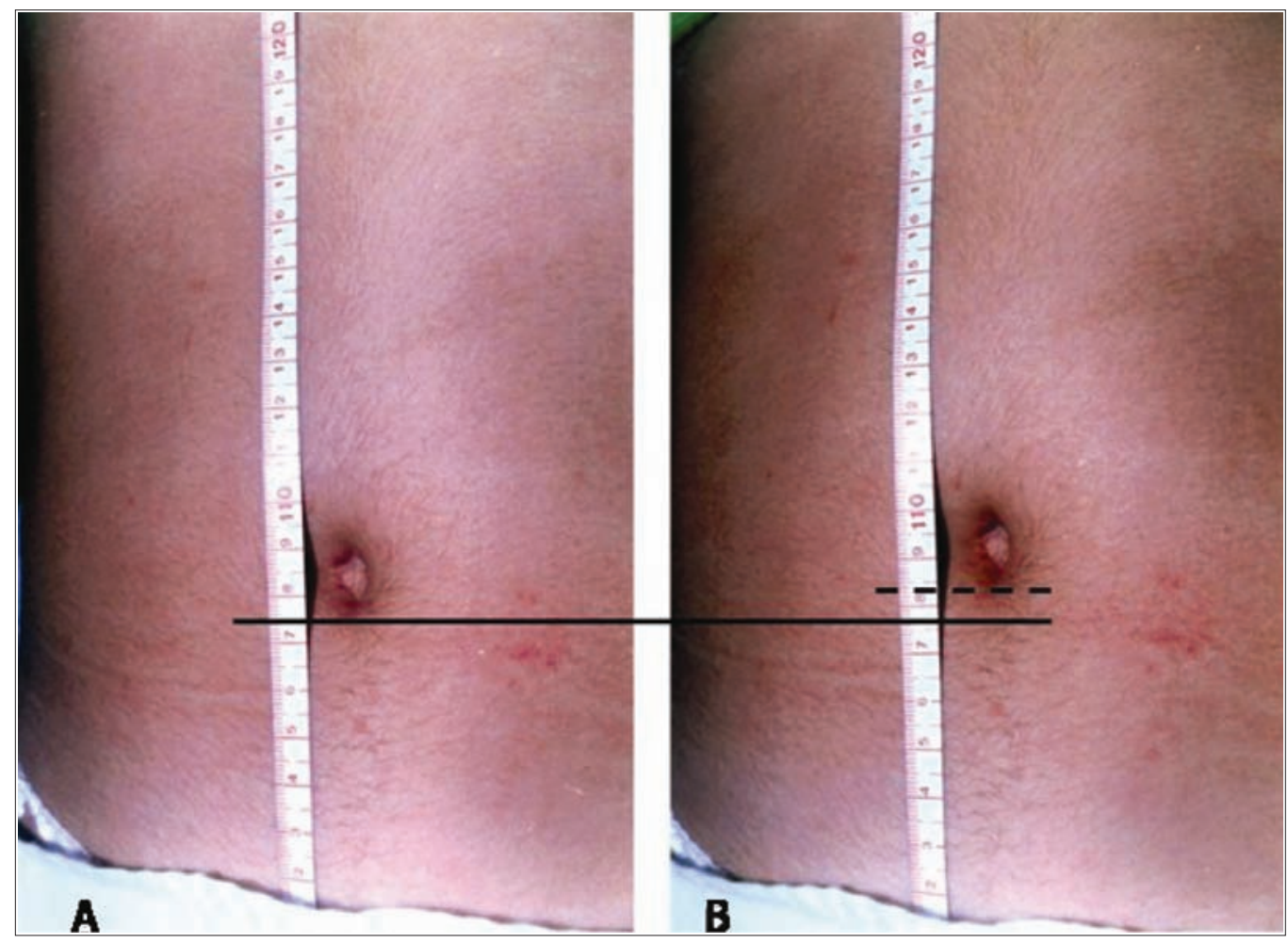

Figure 1. Diagnosis of a spinal cord vascular lesion via Beevor's sign. (A) Position of the umbilicus at rest. (B) Upward Figure 1. Diagnosis of a spinal cord vascular lesion via Beevor's sign. (A) Position of the umbilicus at rest. (B)
movement of the umbilicus $(\sim 1 \mathrm{~cm})$ when the patient contracts the abdominal muscles while trying to sit up.

Multiple sclerosis in Colombia has lower prevalence than neurovascular disorders in general. 2,3 However, to consider a myelovascular attack requires clinical expertise that falls short during rural medical training, which takes place during the last year of mentoring before getting a full practitioner's license in Colombia. The sudden onset, the accompanying signs and symptoms including pain, as well as the Beevor's sign, suggested a vascular lesion inside the spinal cord at around T10 which was confirmed by MRI.

\section{Reprint Requests:}

Dr. Fidias E. Leon-Sarmiento, MD, PhD

Calle 74 No. I5- I5 (201)

Bogota, Colombia

Tel/Fax: 57-I-4006963

Email: feleones@gmail.com
Keywords: Beevor's sign, Neurovascular disease, Spinal cord

Received: January 2, 2007

Accepted: January 26, 2007

doi: $10.3121 / \mathrm{cmr} .2007 .746$

The Aperture, like the opening in the lens of a microscope that allows light to pass through, is a forum for art, humor, and images that provides a portal for new or different views of medicine and research. 
Normally, the umbilicus does not change the position after rectus abdominus contraction. Beevor commented that in spinal cord lesions at the T10 level and below, "When a patient sits up or raises the head from a recumbent position, the umbilicus is displaced toward the head. This is the result of paralysis of the inferior portion of the rectus abdominal muscle, so that the upper fibers predominate pulling upwards the umbilicus."4 Less commonly, downward movement of the umbilicus due to weakness of the upper part of the rectus abdominus muscle is called inverted Beevor's sign. ${ }^{1}$ Beevor's sign has also been described in amyotrophic lateral sclerosis and in some myopathies becoming a very consistent neurological sign in facioscapulohumeral muscular dystrophy. 1,5 In fact, it has been said that in this latter disease, Beevor's sign has $95 \%$ sensitivity and $93 \%$ specificity in neuromuscular diseases. ${ }^{5}$ Neurological signs are still of utmost importance to localized lesions despite novel laboratory techniques. ${ }^{6}$ Curiously, Beevor's most important investigation was on the cerebral blood supply. ${ }^{7}$

\section{References}

1. Hilton-Jones D. Beevor's sign. Pract Neurol 2004;4:176-177.

2. Sanchez JL, Aguirre C, Arcos-Burgos OM, Jimenez I, Jimenez M, Leon F, Pareja J, Pradilla G, Uribe B, Uribe CS, Villa A, Volcy M, Palacio LG. Prevalence of multiple sclerosis in Colombia. Rev Neurol 2000;31:1101-1103.

3. Pradilla G, Vesga BE, Leon-Sarmiento FE, Grupo Geneco. Estudio neuroepidemiologico en Colombia. Bol OPS 2003;14:104-111.

4. Pearce JM. Beevor's sign. Eur Neurol 2005;53:208-209.

5. Shahrizaila N, Wills AJ. Significance of Beevor's sign in facioscapulohumeral dystrophy and other neuromuscular diseases. J Neurol Neurosurg Psychiatry 2005;76:869-870.

6. Leon-Sarmiento FE, Camacho JE, Montoya C, Bayona EA, Bayona-Prieto J. Hemiplegia with two Babinski signs. Medicina (Buenos Aires) 2007: in press

7. Beevor CE. The cerebral arterial supply. Brain 1907;30:403-425.

\section{Author Affiliations}

Fidias E. Leon-Sarmiento, $M D, P h D$

Mediciencia Research Group

Universidad Nacional

Bogota, Colombia; and

Unit of Movement Disorders and Neuromagnetism

Neurology Section

Fundacion Santa Fe

Bogota, Colombia

Edgardo A. Bayona, MD

Mediciencia Research Group

Universidad Nacional

Bogota, Colombia; and

Antonio Narino University

Bogota, Colombia
Jaime Bayona-Prieto, PhT, NRh

Mediciencia Research Group

Universidad Nacional

Bogota, Colombia; and

Faculty of Health

Universidad de Pamplona

Pamplona, Colombia 